\title{
Cellular reprogramming in cardiac diseases: A feather in the hat of regenerative medicine
}

Devendra K. Agrawal, PhD, MBA, and Chandra S. Boosani, PhD

\footnotetext{
From the Department of Clinical and Translational Science, Creighton University School of Medicine, Omaha, Neb.

Supported by a research grants Nos. R01HL112597 and R01 HL128063 to D.K.A. from the National Institutes of Health National Heart, Lung, and Blood Institute. The content of this article is solely the responsibility of the authors and does not necessarily represent the official views of the National Institutes of Health.

Disclosures: Authors have nothing to disclose with regard to commercial support.

Received for publication Sept 27, 2016; accepted for publication Sept 28, 2016; available ahead of print Oct 25, 2016.

Address for reprints: Devendra K. Agrawal, PhD, MBA, Department of Clinical and Translational Science,

CRISS II Rm 510, 2500 California Plaza, Omaha, NE 68178 (E-mail: dkagr@ creighton.edu).

J Thorac Cardiovasc Surg 2017;153:327-8

$0022-5223 / \$ 36.00$

Copyright $(2016$ by The American Association for Thoracic Surgery

http://dx.doi.org/10.1016/j.jtcvs.2016.09.058
}

Myocardial infarction and other heart diseases result in loss of healthy heart tissue and as a consequence there is an increase in the functional burden on the heart that could eventually lead to heart failure and death. In mammals, postnatal proliferation of cardiomyocytes is minimal. The highest proliferation of cardiomyocytes is seen in newborn infants, and their reproduction slows down and nearly halts when an individual reaches the age of about 20 years. ${ }^{1}$ To address pathologic conditions that require cardiac tissue repair and regeneration, there have been significant efforts to induce proliferation of cardiomyocytes - or differentiation of stem cells into cardiomyocytes - and this approach has been found to be therapeutically promising. ${ }^{2-7}$ In a seminal work using lentivirus, mouse fibroblasts were transduced with 3 transcription factors: Gata4, Mef2c, and Tbx5, which resulted in successful cellular reprograming of fibroblasts into cardiomyocytes. ${ }^{8}$ Discovery of cellular phenotype transdifferentiation, especially into cardiomyocytes, was a milestone in cardiac tissue regeneration that heralded the promise of use of cell-based therapy in regenerative medicine.

Mathison and colleagues"9 use of nonintegrative adenoviral vectors for in situ gene transfer into fibroblasts was identified as an effective option compared with the use of lentiviral vectors. The findings from this rat model study describe a concept of cellular reprograming wherein fibroblasts can be trans-differentiated into cardiomyocytes that are usually damaged due to myocardial infarction and in other heart diseases. Importantly, gene delivery of the 3 transcription factors-Gata4, Mef2c, and Tbx5-using adenoviral vectors was shown to outperform the lentiviral system, as observed through increased ejection fraction and improved ventricular function of the heart.

The findings from the study by Mathison and colleagues $^{9}$ address some of the important issues that would make cellular reprogramming a more feasible and effective approach to test in human trials.

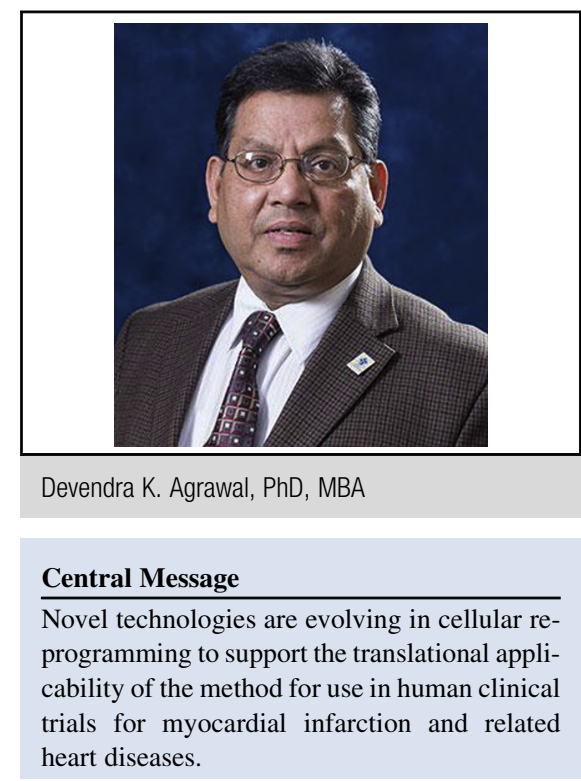

See Article page 329.

1. In addition to the data presented by Mathison and colleagues, ${ }^{9}$ recently the use of adenoviral vectors was found to be more effective in myocardial gene transfer compared with lentivirus or adeno-associated viruses. ${ }^{10}$ Gene therapy using adenoviral vectors in humans has been tested and approved for clinical trials, which adds an advantage to extend the findings from Mathison and colleagues $^{9}$ for clinical trials in humans to induce trans-differentiation of fibroblasts into cardiomyocytes.

2. Use of stem cell therapy for enrichment of cardiomyocytes in damaged tissue requires more invasive procedures compared with gene delivery using viral vectors. On the contrary, adenoviral vectors can be delivered by surface painting the infarct area in addition to intraarterial delivery through catheters.

3. The homing efficiency of delivered stem cells is usually very low. Apparently, stem cells homing into the scar tissue at the infarct site would be very minimal. The fact that fibroblasts invade scar tissue actually favors the cellular reprograming method described by Mathison and colleagues.

4. One of the disadvantages of using stem cells is the difficulty associated with the delivery of stem cells to the target site. A projected complication that is innate to the use of stem cells and that cannot be ignored is the 
possibility of smaller arteries getting occluded by the small cellular clumps during injection of stem cells.

\section{CONCLUSIONS}

Mathison and colleagues ${ }^{9}$ describe an important advancement in the field of cardiovascular translational research that is very promising to improve heart functions through cellular reprogramming. This is an evolving technology and the findings further support the translational applicability of the method for use in human clinical trials for myocardial infarction and related heart diseases.

\section{References}

1. Mollova M, Bersell K, Walsh S, Savla J, Das LT, Park SY, et al. Cardiomyocyte proliferation contributes to heart growth in young humans. Proc Natl Acad Sci U S A. 2013;110:1446-51.

2. Shamblott MJ, Axelman J, Wang S, Bugg EM, Littlefield JW, Donovan PJ, et al. Derivation of pluripotent stem cells from cultured human primordial germ cells. Proc Natl Acad Sci U S A. 1998;95:13726-31.
3. Kehat I, Khimovich L, Caspi O, Gepstein A, Shofti R, Arbel G, et al. Electromechanical integration of cardiomyocytes derived from human embryonic stem cells. Nat Biotechnol. 2004;22:1282-9.

4. Kehat I, Gepstein L. Human embryonic stem cells for myocardial regeneration. Heart Fail Rev. 2003;8:229-36

5. Kehat I, Kenyagin-Karsenti D, Snir M, Segev H, Amit M, Gepstein A, et al Human embryonic stem cells can differentiate into myocytes with structural and functional properties of cardiomyocytes. J Clin Invest. 2001;108:407-14.

6. Zhang J, Wilson GF, Soerens AG, Koonce CH, Yu J, Palecek SP, et al. Functional cardiomyocytes derived from human induced pluripotent stem cells. Circ Res. 2009;104:e30-41.

7. Zwi L, Caspi O, Arbel G, Huber I, Gepstein A, Park IH, et al. Cardiomyocyte differentiation of human induced pluripotent stem cells. Circulation. 2009; 120:1513-23.

8. Ieda M, Fu JD, Delgado-Olguin P, Vedantham V, Hayashi Y, Bruneau BG, et al. Direct reprogramming of fibroblasts into functional cardiomyocytes by defined factors. Cell. 2010;142:375-86.

9. Mathison M, Singh VP, Chiuchiolo MJ, Sanagasetti D, Mao Y, Patel VB, et al. In situ reprogramming to transdifferentiate fibroblasts into cardiomyocytes using adenoviral vectors: Implications for clinical myocardial regeneration. J Thorac Cardiovasc Surg. 2017; 153:317-24.

10. Merentie M, Lottonen-Raikaslehto L, Parviainen V, Huusko J, Pikkarainen S, Mendel M, et al. Efficacy and safety of myocardial gene transfer of adenovirus, adeno-associated virus and lentivirus vectors in the mouse heart. Gene Ther. 2016;23:296-305. 